Original Article

\title{
CONVALESCENT PLASMA THERAPY: A NOVEL APPROACH TO A NOVEL CORONAVIRUS
}

\author{
JOICY JOSE ${ }^{1}$, JOHNSON V. BABU ${ }^{1}$, BHARAT MISHRA ${ }^{2}$
}

1Pharm.D Interns, Nirmala College of Pharmacy, Muvattupuzha. Kerala, 686661, 2Professor and Head, Department of Pharmacology, Nirmala College of Pharmacy, Muvattupuzha. Kerala, 686661

Email: bharatekansh@gmail.com

Received: 01 Jun 2020, Revised and Accepted: 30 Jun 2020

\section{ABSTRACT}

Objective: The Corona virus-induced disease-19 (COVID-19) turning to its aggressive phase of spreading, the treatment options where less and several options are trialing and seeking. Convalescent plasma therapy is one of the newest trailing therapy for COVID patients today without other definite treatment. The convalescent plasma (CP) therapy is used previously and identified its benefits in other conditions. But in the case of COVID 19 the effects and safety should be ensured for its implementation.

Methods: Systematically searched in Pub Med and other authentic sources for articles of interest.

Results: This review includes 5 studies, over all 26 patients who treated CP and following progressions and events. All became clinically better and the antibody titer increased in the patients. Not only that the viral load decreased with a reduction in inflammatory markers

Conclusion: These small studies and case series suggest that CP is effective and safety is high for clinical recover and reduction in viral load.

Keywords: Plasma therapy, Covid-19, Novel Coronavirus, Wuhan, SARS

(C) 2020 The Authors. Published by Innovare Academic Sciences Pvt Ltd. This is an open access article under the CC BY license (http://creativecommons.org/licenses/by/4.0/) DOI: http://dx.doi.org/10.22159/ijpps.2020v12i8.38574. Journal homepage: https://innovareacademics.in/journals/index.php/ijpps.

\section{INTRODUCTION}

SARS CoV-2 (Severe acute respiratory syndrome Corona virus-induced disease 19) being a pandemic, it first emerged in the wet market of Wuhan, China [1]. It is believed that this disease is zoonotic in nature. It is a single-stranded RNA (Ribonucleic acid) virus belonging to the $\beta$ coronavirus family [2]. Management of this disease with a proper treatment protocol or drug is still a challenging task for scientists and physicians. Presently the Convalescent plasma is using in many parts of the world, has approved for the clinical trial. The convalescent plasma therapy uses antibodies from the blood of a recovered patient to treat those critically affected [3]. The therapy can also use to immunize those who were at high risk (health workers, families of patient's contacts). It was used for the severe acute respiratory syndrome (SARS), pandemic 2009 influenza A (H1N1), avian influenza A (H5N1), several hemorrhagic fevers such as Ebola, and other viral infections.

Basic therapy given to patients was monitoring water, electrolyte and oxygen rates continuously and other tests like liver enzymes, urine routine, arterial blood gas, etc. based on severity. The drugs like antiviral, other lifesaving drugs were giving as therapy and oxygen in critical cases as supportive care [4]. At there is not an antiviral agent that specifically act the target receptor. Therefore the importance of convalescent therapy should be discussed [5].

Use of convalescent plasma which is an adaptive immunotherapy in patients affected with severe acute respiratory syndrome [6]. The efficacy and safety of plasma therapy are narrowly understood. Our major aim is to clinically analyze the reported studies of plasma therapy in patients.

\section{MATERIALS AND METHODS}

\section{Methodology}

Systematically reviewed the literature published till April 23rd regarding Novel and innovative therapies of COVID-19, searched by using the keywords COVID-19 therapy, Convalescent plasma therapy, Non Antiviral therapies for COVID 19 by using the popular Internetbased scientific databases such as Science Direct, Pub Med, Springer, Scimago, Elsevier including the Newsletters, correspondence articles etc. The data analysed of 7 studies from 24 articles obtained from
PubMed and excluded 2 because of Chinese language. The studies include case reports, case series and others.

The descriptive analysis includes a total of 5 studies, in each study, we recorded and evaluated author's name, publication year, sample size, participant's details, and trail design, duration of follow, outcome, results and major findings.

\section{RESULTS}

Ahn J. et al. 2020 in their study at Korea, introduces two cases of corona virus-infected patients who improved their disease condition due to the administration of convalescent plasma therapy. In the first case, a COVID-19 positive patient with a history of fever and cough for the past $12 \mathrm{~d}$ was admitted to the hospital. In the initial days, he was treated in a local hospital with $400 \mathrm{mg}$ of HCQ (Hydroxychlorquine) OD (once daily). Further reports of chest X-ray showed mild opacities in the right lower lung, so $400 \mathrm{mg} / 100 \mathrm{mg}$ of lopinavir/ritonavir was included in therapy. Due to the increased oxygen demand, he was transferred to a tertiary hospital.

At the time of admission, he had no complaints of dyspnoea; chest Xray showed bilateral infiltration which was rapidly aggravated. Blood test shows elevated WBC, CRP, lactic dehydrogenase. After $16 \mathrm{~d}, \mathrm{ABG}$ (Arterial blood gas) analysis showed severe ARDS (Acute respiratory distress syndrome) and was treated with IV methylprednisolone 1 $\mathrm{mg} / \mathrm{kg} / \mathrm{d}$. On next day CP $(500 \mathrm{ml})$ from a $20 \mathrm{y}$ old male donor who had been recovered from COVID-19 infection for the past $21 \mathrm{~d}$. After testing of the donor, the plasma was divided into two halves and was administered 12 hourly which took one hour each for administration. Patient's condition was improved from next day onwards and did not experience any adverse drug reactions.

Next case introduces an elderly woman with a history of hypertension who was found to be COVID-19 positive, treated with $400 \mathrm{mg}$ hydroxychloroquine sulphate OD and Lopinavir/Ritonavir $400 \mathrm{mg} / 100 \mathrm{mg}$ BD. She also experienced a similar condition of the above patient and was moved to a tertiary hospital. On the 6th day, she was treated with CP from a 20-year-old donor who had been recovered $18 \mathrm{~d}$ back from COVID-19. She also showed improvement in her condition and chest X-RAY also improved. Both tests cases showed the positive outcome of the use of a convalescent plasma [7]. 
Duan k. et al. 2020 conducted a pilot observational study among COVID-19 patients with a mean age of $53.4 \mathrm{y}$ who is clinically severe patients started convalescent plasma therapy from $11^{\text {th }}$ day of admission. Six males and 4 females were included in the study and 4 had comorbidities. The patients were also treated with antivirals, antibiotics, steroids, antifungal and oxygen therapy. The convalescent plasma samples taken from 40 recovered patients shown that their body contains a high level of antibody titer. The $\mathrm{CP}$ therapy showed a positive outcome like improvement in clinical symptoms and also a reduction in pulmonary lesions. The level of neutralizing antibody tires increased and also showed a high level of the disappearance of SARS CoV-2 RNA virus in the body. On checking with variables of the same age, gender, and severity of the disease, 3 cases were discharged and 7 cases showed much improvement on the discharge process. In the control group, 3 deaths, 6 cases in stabilized status and 1 case in improvement status were reported. Although 2 patients reported mild adverse drug reactions, no too sever adverse drug reactions were reported. Also, there was a reduction in laboratory parameters like ASP, ALP, CRP, lymphocyte and an increase in the saturation of oxygen. The study confirms the efficacy of convalescent plasma in COVID-19 based on its clinical effect and severity in terms of safety [8].

Shen c. et al. 2020 is a case series of 5 patients who were admitted in Shenzhen third people's hospital, China from January 2020-March 25,2020 . Each patient received $200-250 \mathrm{ml}$ of convalescent plasma i.e.; $400 \mathrm{ml}$ in total from 5 donors between the ages of 18-60 y. A total of 5 patients were enrolled in the study with age group 36-73 y and two were females. The CP was administered between $10^{\text {th }}$ and $22^{\text {nd }}$ day of admission. After the CP therapy, one patient becomes negative on post-transfusion day and 2 others become negative in post day 3. Remaining two became negative after $12 \mathrm{~d}$. The inflammatory markers such as CRP, Procalictoin, IL-6 were decreased. Only one them had a chronic disease condition and none were smoker. All of them become clinically better based on the symptoms and radiological examination. None of them reported with an adverse drug reaction. These case series conforms the efficacy and safety of CP therapy among covid-19 patients [9].

Ye M. et al. 2020 conducted their study in six COVID-19 patients who were admitted in Huoshenshan hospital from February 11-12 march. At the time of admission, all patients were administered with drug Arbidol, which is a new antiviral drug. The first patient was treated with Levofloxacin for $3 \mathrm{~d}$ in a local hospital and his temperature became normal. $2^{\text {nd }}$ patient had low oxygen saturation and was administered with oxygen therapy. The fourth patient had history of Sjogren syndrome. Convalescent plasma was collected from COVID-19 recovered patients who were afebrile for at least three days. All the patients received $200 \mathrm{ml}$ of plasma each over 30 min as an infusion. All patients enrolled were having chest abnormalities in CT scan and also their throat swabs were positive Selected patients were from the elderly category expect one who was $28 \mathrm{y}$ of age. No serious adverse drug reactions were noticed in selected patients. After the treatment with $\mathrm{CP}$, there was a drastic improvement in radiology like the resolution of good glass opacities and consolidation in all patients except one patient. Two patients with coronavirus in throat swab elicited the viral load after the therapy $(1,5)$. Increased anti-SARS CoV-2 titre was noticed in two expect one (in $2^{\text {nd }}$ and $3^{\text {rd }}$ patient, not in $1^{\text {st }}$ patient). This study says that convalescent plasma treatment showed good efficacy and safety in clinical terms for COVID positive patients with improvement in their oxygen demand and disease condition [10].

Zhang B. et al. 2020 in their case reports, they introduced 4 critically ill elderly COVID patients (except one who is 31-year-old pregnant female). The first case is of a woman with a history of hypertension, her chest X-ray showed bilateral ground-glass opacity. She was treated with arbidol $200 \mathrm{mg}$ TID, lopinavir/ritonavir $400 \mathrm{mg}$ BD INF-alpha $50 \mathrm{mcg} \mathrm{BD}$ and supportive therapies. Further, due to disease progression, she was shifted to the intensive care unit managed with antibiotics and antifungals due to co-infection. She was diagnosed with septic shock and chest radiographs showed disease progression. A $900 \mathrm{ml}$ of CP was given to the patient in three consecutive times i.e.; $200 \mathrm{ml}, 300 \mathrm{ml}$ and $400 \mathrm{ml}$. The patient was improved and discharged.

Second patient was also treated with arbidol $200 \mathrm{mg}$ TID Lopinavir/ritonavir $500 \mathrm{mg} \mathrm{BD}$, and interferon-alpha 2b. His condition also became severe, with less oxygen capacity and gave mechanical ventilation. The patient was improved and was discharged with further treatment of $200 \mathrm{ml} \mathrm{CP}$. Third case of an old man with a history of hypertension and CKD, he was treated with arbidol $200 \mathrm{mg}$ TID, lopinavir/ritonavir $400 \mathrm{mg}$ BD, oseltamivir 75 mg BD, ribavirin and INF alpha 5 million units BD. The patient was on continuous renal replacement therapy (CRRT). Further, he was diagnosed with multiple organ failure, septic shock and treated with antifungals. Eight transfusions of $2400 \mathrm{ml}$ of $\mathrm{CP}$ was given to the patient. In between the CP therapy patient experienced GI bleeding cystorrhagia, pneumorrhagia. Later, viral load decreased at the time of discharge.

Fourth case is of a pregnant female, at the time of admission, she experienced severe acute respiratory distress syndrome, multiple organ syndrome and septic shock. She underwent invasive ventilation and cesarian was done, but the baby died due to endouterine asphyxia. When she became stable, she was transferred and further investigation showed she had ventricular enlargement and decreased systolic function, also she underwent CRRT. She was treated with lopinavir/ritonavir $400 \mathrm{mg}$ BD, ribavirin $500 \mathrm{mg} 12$ hourly, due to sepsis antibiotics were given. Further, she was clinically improved and discharged with $300 \mathrm{ml}$ of CP therapy. All these cases indicated the efficacy of CP therapy [11].

\section{DISCUSSION}

A total of 26 patients received plasma in various studies, in which 11 were females. The patients are of mean age 57.9 (SD \pm 13.9$)$. Majority of them didn't have any comorbidity. The patients received convalescent plasma as therapy, along with other antivirals and other therapies.

All these cases show the decline in viral load by ELISA and other tests within a few days of CP therapy. The antibody titer was found to be elevated and highly in the blood of patients after receiving the plasma therapy. Not only the significance of antibody and antigen, but the clinical symptoms of patients were also reduced and became better with evidence of chest radiography. The level of inflammatory markers such as CRP, Procalictoin and IL- 6 also found to be rapidly decreasing.

The patient who was in critically ill also become better after the plasma therapy. The adverse drug reaction (3) found is very less and less severe. In COVID-19, without better treatment, plasma therapy can be possible. But it should use early as possible, because the endogenous Immunoglobulin $\mathrm{M}$ and Immunoglobulin $\mathrm{G}$ (IgM and IgG) generated in peak levels at $2-4 \mathrm{w}$ after the infection. The amount of convalescent plasma used in the therapy varied in all studies; actually, it is based on patient factors. Also there is a significant relation with antiviral, steroids and medication along with Plasma therapy. One of the major issue arised when thought this kind of therapy was availability of plasma for the treatment. It should be with certain standards. In all aspects the therapy is successful in small community, but it can't be taken as a fully supported evidence for mass therapy in the community. The long term safety as well increased probability rate of secondary infection should be studied. As the chances of increased rate of secondary infection reported previous week, it should be differentiated in terms of blood transfusion. With a rapidly changing situation, the aftereffects of coronavirus outbreak may lead more serve in sense treatment [12]

If the antibody in the blood is preventing or fighting against the virus it is possible to isolate the antibody and a futuristic antibody compound or vaccine can be generated from this. Its possibility also should be studied. The 26 samples is not enough to finalize the result. The FDA approved a clinical trial for plasma therapy to find out all possible effects and adverse events that can be occurred. 


\section{CONCLUSION}

In the time where all sort of possible treatment options to be explored to save the massive loss of human lives all over the world, the convalescent plasma has emerged as the brightest ray of hope to save the human lives against the COVID-19. The convalescent plasma is previously used in other established therapies, but in this situation, it has been tried and found to be useful and the practices on various centers have proved that it shows the same high level of efficacy and safety. A randomized clinical trial should be done to establish or confirms the treatment of $\mathrm{CP}$ for larger group of patients.

\section{FUNDING}

Nil

\section{AUTHORS CONTRIBUTIONS}

Conception and design: JVB, JJ, Acquisition of data: JVB, JJ, Analysis and interpretation: JVB, JJ, BM, Drafting article: JJ, JVB, BM, Final corrections: BM, JVB, JJ

\section{CONFLICT OF INTERESTS}

The authors declare that there is no conflict of interest.

\section{REFERENCES}

1. Lai CC, Shih TP, Ko WC, Tang HJ, Hsueh PR. Severe acute respiratory syndrome coronavirus 2 (SARS-CoV-2) and corona virus disease-2019 (COVID-19): the epidemic and the challenges. Int J Antimicrobial Agents 2020;55:105924.

2. Malik JK, Kumar A, Soni H. Epidemiology of novel coronavirus (covid-19): a review. J Clin Pharmaco-Epidemiol Res 2020;2:5-13.
3. Tanne JH. Covid-19: FDA approves use of convalescent plasma to treat critically ill patients. Br Med J 2020. DOI:10.1136/ bmj.m1256

4. Al-Tameemi KA, Kabakli R. Novel coronavirus (2019-ncov): disease briefings. Asian J Pharm Clin Res 2020;13:22-7.

5. Parameshwar K, S Pamu, K Sandeep, C Suresh. A review novel coronavirus. Asian J Pharm Clin Res 2020;13:12-7.

6. Kai Duan. Effectiveness of convalescent plasma therapy in severe COVID-19 patients. Proc Natl Acad Sci USA 2020;117:9490-6

7. Ahn JY, Sohn Y, Lee SH, Cho Y, Hyun JH, Baek YJ, et al. Use of convalescent plasma therapy in two covid-19 patients with acute respiratory distress syndrome in korea. J Korean Med Sci 2020;35:e149.

8. Duan K, Liu B, Li C, Zhang H, Yu T, Qu J, et al. Effectiveness of convalescent plasma therapy in severe covid-19 patients. Proc Natl Acad Sci 2020;117:9490-6.

9. Shen C, Wang Z, Zhao F, Yang Y, Li J, Yuan J, et al. Treatment of 5 critically ill patients with covid-19 with convalescent plasma. JAMA 2020;323:1582-9.

10. Ye M, Fu D, Ren Y, Wang F, Wang D, Zhang F, et al. Treatment with convalescent plasma for covid-19 patients in Wuhan, China. J Med Virol 2020. https://doi.org/10.1002/jmv.25882

11. Zhang B, Liu S, Tan $\mathrm{T}$, Huang $\mathrm{W}$, Dong $\mathrm{Y}$, Chen $\mathrm{L}$, et al. Treatment with convalescent plasma for critically ill patients with SARS-CoV-2 infection. Chest 2020;158:e9-e13.

12. Sonali Wairagade BAMS, MD, MRAV, Deepali Giri, Ajay Meshram. facing the deadly pandemic-covid 19 . JCR 2020;7:61-5. 